\title{
Partial interfertility between independently originated populations of the neo-allopolyploid Mimulus peregrinus
}

\author{
Mario Vallejo-Marín ${ }^{1} \cdot$ Mathieu Quenu ${ }^{1} \cdot$ Stuart Ritchie $^{1} \cdot$ Sofie Meeus $^{1}$
}

Received: 6 February 2017/ Accepted: 4 May 2017/Published online: 7 June 2017

(C) The Author(s) 2017. This article is an open access publication

\begin{abstract}
The reduction in genetic diversity in polyploid lineages, formed from whole-genome duplication of a few individuals, can affect their long-term evolutionary potential. Because most polyploids originate multiple times, secondary contact and gene exchange among independently formed polyploids can create novel genetic combinations and reduce the severity of genetic bottlenecks. However, independently originated polyploids may be reproductively isolated from each other due to genetic and chromosomal differences predating the polyploidisation event, or evolving subsequently in the dynamic genomes of young polyploid populations. Here we conducted experimental crosses to investigate the phenotype and interfertility between two independently originated populations of the allopolyploid Mimulus peregrinus (Phrymaceae). We found that individuals from the two populations are phenotypically distinct, but that inter- and intrapopulation crosses are not statistically different. Interpopulation crosses produce viable and fertile offspring, although our results suggest the existence of partial reproductive barriers in the form of reduced pollen viability. We found no difference in pollen viability between F1 and F2 generations. In contrast, we detected a reduction in floral and vegetative size, and in the proportion of plants that flowered, between
\end{abstract}

Handling Editor: Ales Kovarik.

Electronic supplementary material The online version of this article (doi:10.1007/s00606-017-1426-7) contains supplementary material, which is available to authorized users.

Mario Vallejo-Marín

mario.vallejo@stir.ac.uk

1 Biological and Environmental Sciences, Faculty of Natural Sciences, University of Stirling, Stirling FK9 4LA, UK
F1 and F2 generations for both intra- and interpopulation crosses. Together, our results indicate that populations of independent origin can partially exchange genes, producing variable offspring, and that the phenotype of $M$. peregrinus may be unstable in the early generations. Natural selection on genetically based variation may be required for the evolution of more stable and fertile individuals of this nascent allopolyploid.

Keywords Hybridisation - Mimulus · Non-native species · Reproductive barriers · Speciation · Whole-genome duplication

\section{Introduction}

Whole-genome duplication (WGD), or polyploidisation, is an important phenomenon that characterises the evolutionary history of many plants lineages (Levin 2002; Soltis et al. 2009; Jiao et al. 2011). Despite the widespread occurrence of WGD, polyploids need to surmount considerable challenges arising at their origin, including genetic and meiotic instability, minority cytotype disadvantage, and ecological competition with parental taxa (Levin 1975; Ramsey and Schemske 2002; Comai 2005; Arrigo and Barker 2012; Soltis et al. 2014b; Vallejo-Marín and Hiscock 2016). One of the challenges that polyploids need to overcome is the expected reduction in genetic diversity associated with the birth of a polyploid species. Because polyploidisation often results in strong reproductive barriers between the new polyploid and parental taxa due, in part, to differences in chromosome numbers and deregulated expression of imprinted genes (Coyne and Orr 2004; Mallet 2007; Köhler et al. 2010; Lafon-Placette and Kohler 2015), polyploids may be derived from only one or a few 
individuals within a population. Thus, nascent polyploids may carry limited genetic diversity, which in turn might affect their long-term evolutionary potential (Soltis et al. 2014b). This expected reduction in genetic diversity has led to some authors to propose that polyploidisation should be an evolutionary dead end (e.g. Stebbins 1950), and recent work suggests that polyploid lineages have lower rates of speciation than diploid lineages (Mayrose et al. 2011; Arrigo and Barker 2012; but see Soltis et al. 2014a). Yet, the successful establishment of some polyploid lineages indicates that the severity of the challenges associated with the origin of polyploids, including the loss of genetic diversity due to small population sizes at their origin, can sometimes be circumvented.

A principal mechanism that may rescue polyploids from a fate of depauperate evolutionary potential is the fact that polyploid species often have multiple, independent origins (e.g. Wyatt et al. 1988; Soltis and Soltis 1991; Ashton and Abbott 1992; Doyle et al. 1999; Segraves et al. 1999; Beck et al. 2012; Modliszewski and Willis 2012; Sampson and Byrne 2012; Mavrodiev et al. 2015; Servick et al. 2015; Vallejo-Marín et al. 2015). Although each instance of polyploid formation may result in limited genetic diversity, mating between independently generated polyploids may introduce genetic variation into the nascent lineage and create new genetic combinations (Soltis and Soltis 1999). Interfertility between independently originated populations of polyploids is determined by multiple factors. On one hand, genetically distinct populations of polyploids may be reproductively compatible because they share the same parental species (autopolyploids) or combination of species (allopolyploids) and chromosome number. On the other hand, independently originated populations may be isolated from each other by postzygotic reproductive barriers due to genetic or chromosomal incompatibilities that either predate the polyploidisation event or evolve subsequently. For example, nuclear-nuclear and nuclear-cytoplasmic incompatibilities within or between species can result in postzygotic isolation barriers among genetically differentiated populations (Levin 2003; Coyne and Orr 2004; Martin and Willis 2010; Burton et al. 2013; Lindtke and Buerkle 2015). If genetically distinct parental populations of a given parental taxon give rise to separate polyploids, the derived polyploids may be reproductively isolated upon secondary contact. This type of pre-existing barriers may be particularly acute in allopolyploids, as the hybridisation event in each origin may involve different parental taxa as either the maternal or paternal parents, resulting in populations with different combinations of nuclear and cytoplasmic genomes which may interact epistatically (Levin 2003). In addition, postzygotic barriers between independently originated populations may evolve following the polyploidisation event. Polyploid and hybrid genomes can be highly dynamic often undergoing considerable change in gene content, gene expression, and chromosome structure and number in a few generations (Song et al. 1995; Wendel 2000; Ozkan et al. 2001; Tate et al. 2006; Chester et al. 2012; Buggs 2013; Hegarty et al. 2013; Lafon-Placette and Kohler 2015; Soltis et al. 2015; Yant and Bomblies 2015). These rapid genomic changes may result in postzygotic reproductive barriers that impede mating among independently originated populations after they come into secondary contact. Despite the wide recognition that multiple origins characterise many polyploids (but not all, see e.g. Ainouche et al. 2004), few studies have experimentally tested the extent to which populations of separate origin are interfertile (e.g. Modliszewski and Willis 2012).

The recent discovery of the allopolyploid Mimulus peregrinus (Phrymaceae) (Vallejo-Marín 2012) provides an opportunity to experimentally test whether independently originated populations are interfertile. Mimulus peregrinus evolved via hybridisation and genome duplication between two closely related taxa (Vallejo-Marín 2012): the, mostly, diploid Mimulus guttatus $(2 n=28)$ and the ancient tetraploid Mimulus luteus $(2 n=60-64)$ (Vickery 1995). These two species are allopatrically distributed in their native range (North and South America, respectively), but came into secondary contact after they were introduced into the British Isles in the nineteenth century. In the British Isles, M. guttatus and M. luteus form the triploid hybrid Mimulus $\times$ robertsii $(2 n=44-46)$ (Stace 2010), which is highly sexually sterile, but can propagate vigorously through clonality (VallejoMarín and Lye 2013). Mimulus $\times$ robertsii is currently well established and widely distributed in Great Britain (Stace et al. 2015) and can be found in approximately $40 \%$ of all Mimulus populations (Vallejo-Marín and Lye 2013). In the British Isles, $M . \times$ robertsii has given rise, twice, to a new species: the sexually fertile allohexaploid $M$. peregrinus $(2 n=92)$ (Vallejo-Marín et al. 2015). Because the earliest records of naturalised populations of $M . \times$ robertsii date back to the 1870s (Preston et al. 2002), it is likely that $M$. peregrinus is a recently formed allopolyploid less than 150 years old. Mimulus peregrinus (= Erythranthe peregrina) has been found in southern Scotland (South Lanarkshire) and the Orkney Isles off the north coast of Scotland, two regions separated by approximately $400 \mathrm{~km}$. Within each of these regions, $M$. peregrinus occurs in multiple localities separated by a few kilometres. Genomic analyses of $M$. peregrinus from South Lanarkshire and Orkney indicate that this allopolyploid species has originated in each of these two regions, independently, and is closely related to sympatric (Leadhills) or nearby (Orkney) populations of $M . \times$ robertsii (Vallejo-Marín et al. 2015).

Recent analyses of the cytoplasmic genomes of $M$. peregrinus have shown that all sampled individuals carry 
chloroplast and mitochondria inherited from M. guttatus, suggesting that the hybridisation event involved in the origin of this allopolyploid had M. guttatus as the maternal parent and $M$. luteus as the paternal one (Vallejo-Marín et al. 2016). Consistent with this observation, natural populations of $M . \times$ robertsii also tend to have $M$. guttatus mitochondria and chloroplasts, and experimental crosses between M. guttatus and M. luteus show that hybrids are much easier to produce when M. guttatus is the mother than in the opposite direction (Vallejo-Marín et al. 2016). The observed pattern of asymmetric hybridisation in $M$. peregrinus is common in interploidy crosses (VallejoMarín and Hiscock 2016), although in many cases, hybrids are more likely to be viable when the maternal parent is of higher ploidy than the paternal parent (Köhler et al. 2010), opposite to what has been observed in $M . \times$ robertsii (Vallejo-Marín et al. 2016). The mechanism for the formation of $M$. peregrinus is unknown, but it may have evolved either via somatic doubling or via mating of unreduced gametes of $M . \times$ robertsii. Although highly sterile, $M . \times$ robertsii occasionally produces unreduced gametes (M. Vallejo-Marin and A. Laing unpublished data), which potentially could produce a polyploid individual. In summary, $M$. peregrinus is a newly evolved allopolyploid for which the origin and genetic composition of different populations are relatively well characterised. Moreover, M. peregrinus can be easily grown in experimental conditions and has a short generation time (as fast as 8 weeks from seed to seed), which makes it suitable for experimental tests carried over multiple generations. For the present study, we conducted experimental pollinations and grew individuals from both intra- and interpopulation crosses in common gardens to determine whether independently originated populations of a newly evolved allopolyploid $M$. peregrinus are interfertile. We also analysed germination, fertility, phenology, and floral and leaf morphology of parental populations and two generations of intra- and interpopulation crosses to characterise the phenotype of $M$. peregrinus.

\section{Materials and methods}

We studied two populations of $M$. peregrinus. The first population (LED; latitude: $55.423^{\circ}$, longitude: $-3.735^{\circ}$ ) is located in southern Scotland and is the place where $M$. peregrinus was first discovered (Vallejo-Marín 2012). The second population (STR) is in the Orkney Isles near the town of Stromness $\left(58.969^{\circ},-3.283^{\circ}\right)$. We have previously shown that these two populations are genetically differentiated and represent separate, independent origins of M. peregrinus, from local triploid M. × robertsii (Vallejo-Marín et al. 2015). For each of the two populations, we selected five maternal seed-families, i.e. groups of seeds derived from the same maternal parent. The maternal families were either directly collected from in the field (STR) or derived from 1-2 generations of selfing of fieldcollected individuals (LED) (Table 1).

Seeds were planted in 9-cm-diameter plastic pots filled with Modular Seed compost (Sinclair, Lincoln Lincolnshire, UK) on 1 July 2014 and placed in a controlled environment cabinet (Snijder Microclima). The growth cabinets were kept at $24{ }^{\circ} \mathrm{C} / 16 \mathrm{~h}$ light and $16{ }^{\circ} \mathrm{C} / 8 \mathrm{~h}$ dark cycles with $70 \%$ relative humidity and $80 \%$ illumination. After approximately 9 days, individual seedlings were transplanted to $9 \mathrm{~cm}$ pots filled with General Purpose compost (Sinclair) and placed in flooded plastic trays in the glasshouse. Supplemental lighting was provided by compact fluorescent lamps during $16 \mathrm{~h}$ each day. These individuals formed the parental $(\mathrm{P})$ generation.

To generate the F1 generation, we conducted controlled pollinations both within and between populations in the $\mathrm{P}$
Table 1 Parental accessions (P) of Mimulus peregrinus used in the experiment

\begin{tabular}{lll}
\hline Maternal seed family ID & Population & $\begin{array}{l}\text { Source of individuals } \\
\text { in P generation }\end{array}$ \\
\hline 11-LED-seed-1-54 & Leadhills & $\mathrm{S} 2$ \\
11-LED-seed-2-14 & Leadhills & $\mathrm{S} 2$ \\
11-LED-seed-2-19 & Leadhills & $\mathrm{S} 2$ \\
11-LED-seed-4-5 & Leadhills & $\mathrm{S} 2$ \\
11-LED-seed-5-17 & Leadhills & $\mathrm{S} 2$ \\
11-LED-seed-19 & Leadhills & $\mathrm{S} 1$ \\
13-STR-seed-1 & Stromness & Field collected \\
13-STR-seed-2 & Stromness & Field collected \\
13-STR-seed-3 & Stromness & Field collected \\
13-STR-seed-4 & Stromness & Field collected \\
13-STR-seed-5 & Stromness & Field collected \\
\hline
\end{tabular}

The source of each maternal family is indicated as field collected or derived from one (S1) or two (S2) generations of selfing 




Fig. 1 Simplified diagram of the crossing design used in the experiment. Straight arrows denote self-pollination. Joining arrows are cross-pollinations. The Leadhills individuals used in the parental (P) generation are first- and second-generation lines from field- collected seed (bulk collected) in 2011. The Stromness individuals in the $\mathrm{P}$ generation were grown from field-collected seed sampled in 2013 from individually collected maternal parents

20; Mitutoyo, Japan) to the nearest $0.01 \mathrm{~mm}$, except leaf size, which was measured with a ruler to the nearest $0.5 \mathrm{~cm}$

The viability of $\mathrm{F} 1$ seeds resulting from controlled pollinations was assessed in seed families from 10 interpopulation (five in each direction) and eight intrapopulation crosses (four crosses per population). Here we use seed germination as an estimate of seed viability. For each family, we planted an average of 74 seeds (range $=30-157$ ) in a controlled environment cabinet at $24{ }^{\circ} \mathrm{C} / 18 \mathrm{~h}$ light and $16{ }^{\circ} \mathrm{C} / 6 \mathrm{~h}$ dark cycles with $70 \%$ relative humidity and $80 \%$ illumination. We counted the number of emerged seedlings 14 days after planting and calculated the probability of germination (number of seeds that germinated over the total number of seeds planted) per family.

To estimate pollen fertility in F1 and F2 individuals, we collected five mature anthers from a single flower in 1.5$\mathrm{mL}$ microcentrifuge tubes with $1 \mathrm{~mL}$ of $70 \%$ ethanol. Pollen was stained with $100 \mu \mathrm{L}$ lactophenol-aniline blue (Kearns and Inouye 1993) and scored in a compound microscope (Olympus, Hamburg, Germany) at 400x magnification. Pollen that was evenly stained blue was considered viable, and pollen that was not stained or with a few irregular blue patches was considered inviable. Nonstained pollen was usually smaller and/or appeared malformed (not spherical). Hereafter we use this measure of pollen stainability as an estimate of pollen fertility. In each sample, we counted at least 200 pollen grains (mean $=230$ grains). Biomass was estimated in F1 and F2 plants after plants had begun senescing in July-August 2015. All above-ground biomass was harvested from each individual and placed in a drying oven at $40{ }^{\circ} \mathrm{C}$ for $72 \mathrm{~h}$, and weighted in an OHAUS-Analytical Plus digital balance (GmbH, Nanikon, Switzerland). 


\section{Statistical analyses}

\section{Parental generation}

We conducted a principal component analysis (PCA) of nine morphological variables (traits 1-9 above) using the function princomp in the statistical package $R$ (R Development Core Team 2016). We analysed statistical differences in the first two principal components between populations (LED and STR) using a generalised linear mixed effects model in the package lme4 (Bates et al. 2015). Plant identity and maternal family were used as random effects, and population of origin as a fixed effect. Days to flower were compared between populations using maternal family as a random effect. Statistical significance of the fixed effect was assessed with lmerTest (Kuznetsova et al. 2016) using a Satterthwaite approximation for degrees of freedom.

\section{Seed viability of F1 generation}

The viability of F1 seeds was analysed using a binomial model with logit link. The significance of cross type $($ LED $\times$ LED, STR $\times$ STR or STR $\times$ LED) was assessed using a likelihood ratio test with two degrees of freedom.

\section{Phenotype and fertility of the F1 and F2 generations}

We analysed phenotype and fertility for the F1 and F2 generations jointly. We conducted a PCA on the same nine morphological variables as in the $\mathrm{P}$ analysis. The first principal component, as well as pollen viability and biomass, was analysed using generalised linear Markov Chain Monte Carlo models using the $R$ package MCMCglmm (Hadfield 2010). We chose to use generalised mixed effects models in MCMCglmm because it allowed us to incorporate complex pedigree information in the specification of the error structure. Thus, this analysis explicitly accounts for the relationships between individuals in F1 and F2 generations. In all analyses, cross type (i.e., LED $\times$ LED, STR $\times$ LED, STR $\times$ STR) was included as a fixed effect. Cross type and generation (F1, F2) were included as fixed effects, and individual as a random effect. For the analysis of the first principal component, days to flower, and biomass, we used a Gaussian distribution and default priors, and for pollen viability we used a multinomial distribution ("multinomial2") and the following priors for the random effect (individual): $V=1, v=0.002$. All models were run for 1000,000 iterations with a 50,000 burn-in period, and thinning every 100 iterations. The statistical significance of the fixed effects was assessed using MCMC " $P$ values". Pairwise comparisons between specific "cross type" levels (e.g. STR $\times$ LED vs. LED $\times$ LED) were assessed by using one of those levels as the reference (intercept) in the model, calculating the difference in posterior parameter estimates between each two levels (i.e., STR $\times$ LEDLED $\times$ LED) for the $1,000,000$ iterations of the model, and calculating whether the $95 \%$ credible interval of this difference overlapped zero.

\section{Results}

\section{Phenotypic differentiation between populations of Mimulus peregrinus}

The first (PC1) and second principal components (PC2) explained 27 and $24 \%$ of the variation in the nine measured floral and vegetative traits of the parental, $\mathrm{P}$, generation (Table 2a). The first principal component was positively associated with larger values of all nine traits, and thus serves as an overall indicator of size and of flowering at later nodes. The second principal component was correlated with larger leaves and flowering at later nodes, and smaller calyces and corollas. A bivariate plot of PC1 and PC2 suggests a clear overall differentiation between the population of M. peregrinus from southern Scotland (LED) and the Orkney population (STR) (Fig. 2). Individuals

Table 2 Loadings of the first two principal components (PC1 and PC2) of a principal component analysis of floral and vegetative characters of (a) two parental $(\mathrm{P})$ populations of Mimulus peregrinus and (b) F1 and F2 generations of both within- and between-population crosses of these populations, grown in a common garden

\begin{tabular}{lrr}
\hline & PC1 & PC2 \\
\hline (a) & & \\
Flowering node & 0.394 & 0.388 \\
Pedicel length & 0.230 & -0.316 \\
Corolla width & 0.519 & -0.161 \\
Corolla height & 0.424 & -0.298 \\
Corolla tube & 0.044 & -0.592 \\
Anther-stigma distance & 0.406 & 0.135 \\
Calyx length & 0.168 & -0.312 \\
Second node leaf length & 0.367 & 0.354 \\
Second node leaf width & 0.114 & 0.206 \\
(b) & & \\
Flowering node & 0.253 & -0.422 \\
Pedicel length & 0.397 & 0.009 \\
Corolla width & 0.493 & 0.022 \\
Corolla height & 0.486 & 0.079 \\
Corolla tube & 0.419 & 0.010 \\
Anther-stigma distance & 0.178 & 0.082 \\
Calyx length & 0.286 & 0.003 \\
Second node leaf length & 0.095 & 0.627 \\
Second node leaf width & -0.039 & 0.645 \\
\hline
\end{tabular}




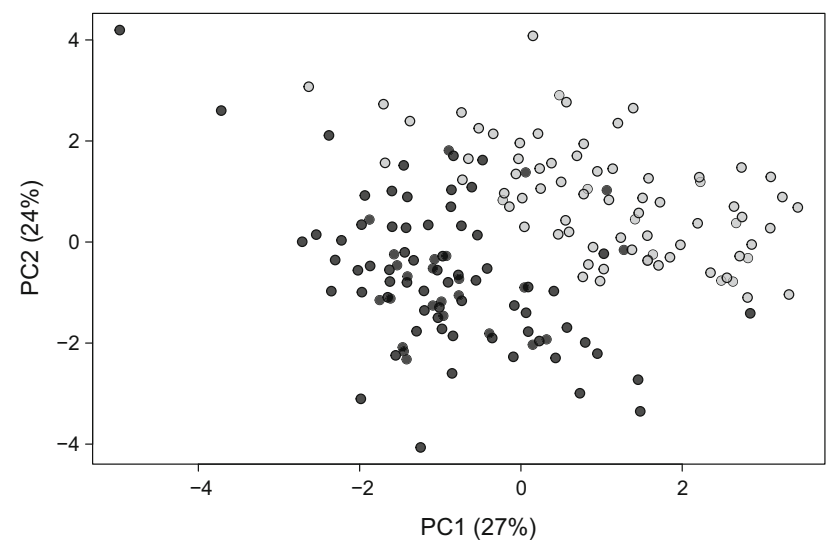

Fig. 2 Scatterplot of the first two components of a PCA of floral and vegetative traits in the parental generation $(\mathrm{P})$ of two independently originated populations of Mimulus peregrinus. Grey symbols: population from Stromness, Orkney (STR); black symbols: population from Leadhills, South Lanarkshire (LED), Scotland. The proportion of variance explained by each component is given in parenthesis. Sample size: 168 flowers, 84 individuals (46 from LED, 38 from STR)

from STR had significantly larger values than LED individuals for both PC1 (STR regression coefficient $=2.02 \pm 0.28$, mean \pm S.E.; $P<0.001)$ and PC2 (STR regression coefficient $=1.56 \pm 0.32 ; \quad P<0.01$ ). Among plants that flowered in our experiment, STR individuals took an average of 3 days longer to produce their first flower $(41.76 \pm 0.31$ vs. $38.00 \pm 0.44$, for STR and LED, respectively; $P<0.01$ ). Together, our results suggest that $M$. peregrinus from Orkney is generally larger and produces flowers later and in higher nodes than the southern population, although there is variation among individual traits (Fig. 3).

\section{Germination of within- and between-population crosses}

Both within- and between-population crosses produced viable seeds and had similar germination rates. Germination for crosses between populations $($ LED $\times$ STR) seeds was $75 \% \pm 7$, and for within population crosses was $71 \% \pm 10($ LED $\times$ LED $)$ and $74 \% \pm 9($ STR $\times$ STR $)$. These differences were not statistically significant as assessed with a likelihood ratio test $(P=0.561)$.

\section{Floral and vegetative phenotype of $\mathrm{F} 1$ and $\mathrm{F} 2$ generations}

Scatterplots of individual floral and vegetative traits in the F1 and F2 generation are shown in Online Resources 1 and 2. The PCA of the morphological data across the F1 and F2 generations summarised 59\% of the variation in the first and second principal components. The first principal component (PC1) was correlated with larger values of all floral traits and with flowering at later nodes, and only weakly with vegetative traits (longer and narrower leaves), explaining $37 \%$ of the variation (Table $2 b$ ). As in the parental generation, STR individuals had larger PC1 values indicating larger floral traits, and flowering at later nodes than LED individual $(0.88 \pm 0.18$ vs. $-0.76 \pm 0.17$, for STR and LED, respectively). The interpopulation crosses had PC1 values intermediate between the parental populations $(0.29 \pm 0.20)$. However, the MCMC analysis of PC1 using the pedigree information did not find statistically significant differences between the different cross types $(P>0.13$; Fig. $4 \mathrm{a})$. The second principal component explained $22 \%$ of the variation; it was negatively and strongly associated with leaf size, and only weakly and negatively associated with floral traits. The second principal component (PC2) was positively associated with flowering at later nodes. PC2 was smaller for LED than for STR $(-0.42 \pm 0.15$ vs. $0.05 \pm 0.16$, respectively), suggesting that LED produces shorter and narrower leaves than STR. The cross LED $\times$ STR had the largest average values for PC2 $(0.40 \pm 0.14)$ suggesting that the interpopulation cross had larger leaves and flowered at later nodes than the intrapopulation crosses. Nevertheless, the MCMC analysis did not show statistically significant differences between the crosses $(P>0.05)$. Finally, we found a significant effect of generation on PC1 but not on PC2, with $\mathrm{F} 2$ individuals having smaller $\mathrm{PC} 1$ values than $\mathrm{F} 1$ plants $(P<0.001$; Fig. 4a).

Average days to flower in the F1 and F2 generations were nearly identical between LED $\times$ LED and STR $\times$ LED crosses $\quad(42.45 \pm 0.26$ days vs. $42.39 \pm 0.24$ days, respectively), while STR $\times$ STR individuals took slightly longer to produce the first flower (43.89 \pm 0.21 days). These differences were not statistically significant $(95 \%$ credible intervals of effect size differences overlap zero).

\section{Pollen viability and biomass of F1 and F2 generations}

We found no statistically significant differences in pollen viability between LED $\times$ LED and STR $\times$ STR $($ Fig. $4 c)$. Average pollen viability in STR x STR individuals across both F1 and F2 generations was $0.76 \pm 0.04$ vs. $0.63 \pm 0.04$ for LED $\times$ LED individuals. The pollen viability of interpopulation hybrids STR $\times$ LED was 0.50 , which was significantly lower than STR $\times$ STR, but not distinguishable from LED $\times$ LED plants (Fig. $4 c$ c). We found no significant differences in pollen viability between F1 and F2 (Fig. 4c).

Average dry biomass across F1 and F2 generations was $3.19 \mathrm{~g} \pm 0.15 \quad($ STR $\times$ STR $), \quad 2.51 \mathrm{~g} \pm 0.10$ 
$P$


Fig. 3 Floral and vegetative characteristics of individuals of Mimulus peregrinus from two independently originated populations: Leadhills, South Lanarkshire (LED); and Stromness, Orkney (STR). The error bars represent the means and $95 \%$ confidence intervals calculated using a nonparametric bootstrap (1000 replicates). A small amount of jitter has been added to the $x$-axis to improve the visualisation of data points. All measurements in mm, except flowering node, which is the number of nodes counted from the base of the plant to the first flower. $A S D$ anther-stigma distance, $P$ parental generation. Sample size as in Fig. 1
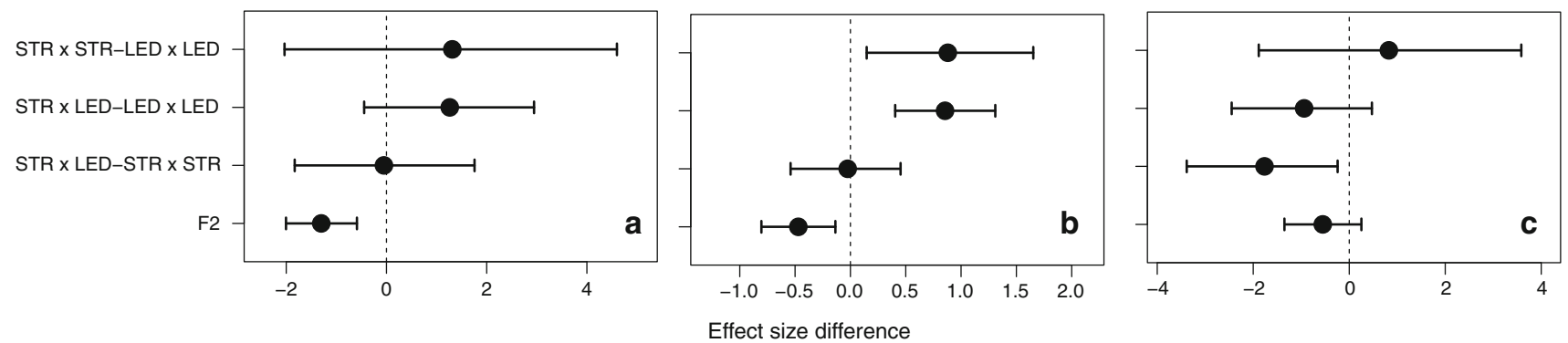

Fig. 4 Effect size differences in pairwise comparisons of phenotype and fertility between different types of intra- and interpopulation crosses of independently originated populations of Mimulus peregrinus (LED and STR) obtained using MCMC generalised linear mixed models. Pairwise comparisons between specific "cross type" levels (e.g. STR $\times$ LED vs. LED $\times$ LED) were assessed by calculating the difference in posterior parameter estimates between each two levels (i.e., STR $\times$ LED-LED $\times$ LED) for 1,000,000 iterations of the model, and calculating the $95 \%$ credible interval. Intervals that do not overlap zero are interpreted as statistically significant. The credible interval for F2 indicates differences in trait value between the F1 and F2 generation across all cross types. a Results for the model of the first principal component (PC1). Sample sizes: F1 generation: 81 (49), 57 (37), and 30 (24) [number of flowers (number of individuals) for LED $\times$ LED, STR $\times$ LED, and STR $\times$ STR, respectively]; F2 generation: 13 (7), 35 (22), and 20 (13). b Model results for aboveground dry biomass. c Model results for pollen viability 
$(\mathrm{LED} \times \mathrm{LED})$, and $3.24 \mathrm{~g} \pm 0.12(\mathrm{STR} \times \mathrm{LED})$. In pairwise comparisons, dry biomass of STR $\times$ STR was significantly higher than LED $\times$ LED, but no different from interpopulation crosses. In contrast, STR $\times$ LED produced significantly more dry biomass than LED $\times$ LED (Fig. 4b). We also found a significant reduction in dry biomass in the F2 (3.03 $\mathrm{g} \pm 0.9$ vs. $2.79 \mathrm{~g} \pm 0.15$, for $\mathrm{F} 1$ and F2, respectively; Fig. 4b), but no interaction between cross type and generation (results not shown).

\section{Discussion}

\section{Interfertility of Mimulus peregrinus of independent origin}

Here we have shown that independently originated populations of the neo-allopolyploid Mimulus peregrinus are interfertile, i.e., produce viable, fertile offspring. Although there is ample genetic evidence of multiple origins across a variety of allopolyploid taxa (e.g. Wyatt et al. 1988; Ashton and Abbott 1992; Franzke and Mummenhoff 1999; Segraves et al. 1999; Soltis et al. 2004; Beck et al. 2012; Mavrodiev et al. 2015; Servick et al. 2015; Vallejo-Marín et al. 2015), fewer studies have experimentally compared the interfertility of independently originated populations. For instance, Modliszewski and Willis (2012) investigated the interfertility of populations of independent origin of the allotetraploid Mimulus sookensis $(2 n=4 x=56)$, which is the polyploid derivative of hybrids between $M$. guttatus and $M$. nasutus $(2 n=28)$ (Benedict et al. 2012). Modliszewski and Willis crossed four populations of $M$. sookensis and compared the pollen viability of F1 and outbred F2 individuals grown in a common garden. The average pollen viability of F1 individuals was similar to mean parental values (95.2 vs. $96.8 \%$, for $\mathrm{F} 1$ and the average of both parents, respectively) and was slightly lower in F2s (93.3\%, range: 89-94\%) (Modliszewski and Willis 2012). The reduction in pollen fertility in the F2s was statistically significant in three of the six crosses analysed in $M$. sookensis. In the case of $M$. peregrinus, pollen viability of interpopulation crosses was reduced by approximately $30 \%$ (50 vs. $69 \%$ pollen viability for interpopulation crosses vs. average pollen viability of both parental populations), while pollen viability was not significantly different between F1 and F2 generations.

Although interpopulation crosses of $M$. peregrinus are fertile, the observed reduction in pollen viability indicates the existence of partial postzygotic isolation barriers to gene exchange between independently originated polyploid populations. Such barriers could arise from a variety of mechanisms and either predate the formation of the allopolyploids or evolve subsequently. For example, postzygotic reproductive barriers occur among some genetically differentiated populations of the same species, due to nuclear-nuclear or nuclear-cytoplasm incompatibilities that are expressed in the interpopulation crosses (Rieseberg and Willis 2007; Burton et al. 2013). In Mimulus guttatus, one of the parental species of M. peregrinus, reduced pollen viability is sometimes expressed in interpopulation crosses (Fishman and Willis 2006; Sweigart et al. 2007). Reduced pollen fertility in intraspecific crosses of $M$. guttatus is thought to arise through Dobzhansky-Muller incompatibilities between populations either from nuclear-nuclear or nuclear-cytoplasmic interactions (Martin and Willis 2010). Mimulus peregrinus could inherit these preexisting genetic incompatibilities from its parental taxa causing lower pollen fertility when independently originated populations are crossed. Currently there is no data to evaluate the level of reproductive isolation between populations of $M$. guttatus in the UK. However, genomic analyses indicate that UK populations of $M$. guttatus are closely related to each other, and that most UK populations may be derived from a similar geographic region (Puzey and Vallejo-Marín 2014; Pantoja et al. 2017). Future work addressing potential hybridisation barriers within introduced $M$. guttatus would help understand the extent to which gene flow among independently originated populations of allopolyploids is limited by preexisting genetic incompatibilities.

An additional mechanism that could explain the observed reduction in pollen viability in interpopulation crosses of $M$. peregrinus is the evolution of genomic differences between populations following the allopolyploidization events. For example, polyploid genomes often undergo extensive modification through the loss of genes (Buggs et al. 2009; Koh et al. 2010), chromosome fragments, and entire chromosomes (Lim et al. 2008; Chester et al. 2013). Moreover, even in the absence of gene loss, chromosomal rearrangements evolving in hybrid and polyploid genomes can result in postzygotic isolation in crosses between populations fixed for different chromosome rearrangements (Soltis and Soltis 1999; Rieseberg 2001). Genome fractionation (the loss of duplicated genes), chromosome loss, and genomic rearrangements can occur rapidly, in a few generations, as has been shown in studies of synthetic allopolyploids in Tragopogon (Lim et al. 2008; Buggs et al. 2009), Brassica (Song et al. 1995), Triticum, and Aegilops (Liu et al. 1998), although other synthetic allopolyploids such as those recreating $M$. sookensis show little evidence of gene loss in the first generations (Modliszewski and Willis 2014). In M. peregrinus, there is preliminary evidence suggesting that this young allopolyploid has undergone some level of genome reorganisation (Vallejo-Marín et al. 2015). Using a sequence-capture approach to sequence a small subset of the genome at high 
depth, Vallejo-Marín et al. (2015) compared the genotypes of $M$. peregrinus from the Leadhills (LED) and Stromness (STR) populations to their corresponding local triploid ancestors $(M . \times$ robertsii). They found that for 40 out of 6434 SNPs that were heterozygous in $M . \times$ robertsii, one of the parental alleles was missing in the corresponding $M$. peregrinus. Interestingly, most of the loci with a missing allele (24/40) were restricted to an individual from the STR population and were mapped to a single chromosome (linkage group 14). To the extent that the missing alleles represent the local loss of part of one of the parental subgenomes, these results would indicate that LED and STR have genetically diverged following the polyploidisation event. This type of genetic divergence through the loss of genetic material following polyploidisation could provide a mechanism to explain the partial postzygotic barriers observed among independently originated populations of M. peregrinus.

\section{Changes in phenotype across two consecutive allopolyploid generations}

The analysis of the phenotype and fertility of both F1 and F2 generations of inter- and intrapopulation crosses grown simultaneously in a common garden offers some insight into the phenotypic stability of $M$. peregrinus across generations. The observed reduction in size from the F1 to the F2 generation in both intra- and interpopulation crosses may indicate the early symptoms of hybrid breakdown (Burton et al. 2013) in M. peregrinus. The traits involved included floral and leaf characters - as measured by the principal component analysis - and above-ground biomass. The reduction in these traits affected equally inter- and intrapopulation crosses (generation $\times$ cross type interaction was not statistically significant; $P>0.28$ for both PC1 and biomass). A reduced performance of $\mathrm{F} 2$ individuals was also suggested by the lower fraction of individuals that flowered in our experiment in the $\mathrm{F} 2$ versus the $\mathrm{F} 1$ generation ( $46 \% \pm 0.04$ vs. $30 \% \pm 0.06$, in the F1 and F2 generations, respectively), although the average day to first flower of those individuals that flowered was nearly identical in the F1 and F2. However, despite the reduction in size and proportion of flowering individuals in the F2, we found no statistically significant evidence of a reduction in pollen viability, suggesting that changes in plant size are not necessarily associated with reduced fertility in $M$. peregrinus.

Reduced viability or fertility in some F2 genotypes is well documented in homoploid hybrids (Grant 1966; Rieseberg et al. 1996; Burke et al. 1998; Burke and Arnold 2001), but less is known about how the fitness of allopolyploid taxa changes across early generations (Grant 1971; Comai et al. 2000; Madlung et al. 2005; Henry et al. 2014). Artificially created allopolyploids often suffer from low fertility and viability and display phenotypic instability (Madlung et al. 2005). In theory, allopolyploids may display reduced vigour and pollen viability in early generations as they accumulate chromosomal abnormalities, e.g. aneuploidy, due to the complexity of pairing and segregation during mitosis and meiosis (Grant 1971; Comai 2005; Madlung et al. 2005; Buggs et al. 2009; Madlung 2013). In addition, variation in patterns of gene loss (Buggs et al. 2012) and/or levels of gene expression could also rapidly produce phenotypic variation and lower fitness in early generation allopolyploids, even in the absence of large chromosomal abnormalities (Comai et al. 2000; Hegarty et al. 2006; Hegarty and Hiscock 2008; Buggs et al. 2011). For instance, synthetic allopolyploids of Arabidopsis thaliana $\times$ Arabidopsis arenosa ("Arabidopsis suecica") display phenotypic variation in the F2 in flower and leaf morphology, phenology, and pollen fertility, and at least some of this variation is thought to be associated with gene silencing (Comai et al. 2000) and may involve changes in transposon activity (Madlung et al. 2005). Variation in fertility in the F2 generation of allopolyploids can also arise due to segregation of Mendelian loci in interpopulation crosses of different origins. Again, in the allopolyploid A. suecica, F2s between natural and synthetic lines display variation in pollen viability. This variation is associated with the stability of meiosis in F2s and correlates with segregation at a single quantitative trait locus (BOY NAMED SUE) (Henry et al. 2014). Natural allelic variation for genes controlling meiotic stability are well studied in autopolyploids (Yant et al. 2013; Wright et al. 2015) and in a few allopolyploids (Hollister 2015). In addition, because F2s in our experiment were generated by self-fertilisation, it is also possible that phenotypic changes are partly due to increased homozygosity within subgenomes compared to the F1 generation. Therefore, the phenotype and genotype of recently formed allopolyploids may vary across generations due to the action of one or more of several mechanisms including rapid changes in chromosome number and structure, modification of gene expression, inbreeding, and segregation of genes involved in meiotic stability.

Variation in the phenotype of advanced generation allopolyploids in fitness-related traits, including pollen viability, has important implications for the evolutionary fate of nascent polyploid lineages. For instance, although average fertility in the F2 is $\sim 50 \%$, some of the F2 individuals from both inter and intrapopulation crosses in $M$. peregrinus have high fertility (>70\%) (Fig. 5). It has long been recognised that even when hybrids have on average lower fitness than their parental taxa (Coyne and Orr 2004), some hybrids can have equal or higher fitness than parental classes (Arnold and Hodges 1995; Burke and Arnold 2001; Arnold and Martin 2010). In these cases, natural selection 
F1

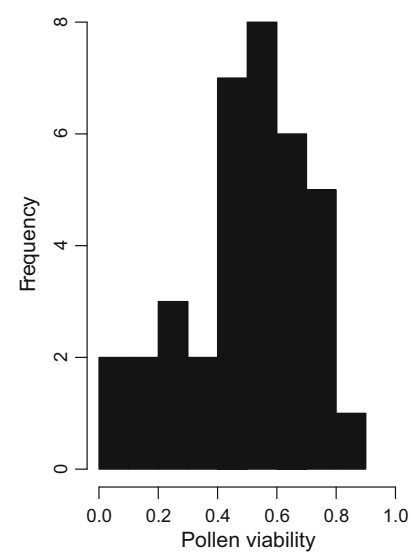

F2

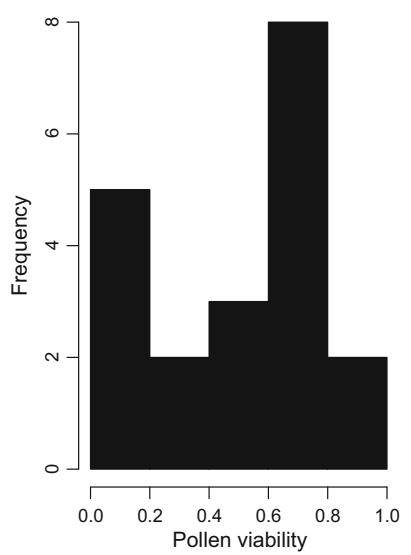

Fig. 5 Frequency distribution of the proportion of viable pollen in interpopulation crosses between two independently originated populations of Mimulus peregrinus, measured in the F1 and F2 generations (110 flowers and 42 flowers, respectively)

on the viability and fertility of segregating allopolyploids may favour the persistence of nascent lineages, allowing them to escape a "bottleneck of instability" and to become established in the long term (Ramsey and Schemske 2002; Comai 2005). The extent to which M. peregrinus can evolve higher fertility and viability through natural or artificial selection remains to be determined. Further work comparing fitness-related traits of $M$. peregrinus and its parents, including survivorship, pollen and seed viability, and clonal propagation, ideally under field conditions, is needed to establish the evolutionary fate of this nascent species. Furthermore, the increased availability of genomic resources in Mimulus offers the opportunity to search for links between phenotype and genotype in M. peregrinus. Such studies are needed to identify how potential changes in genome structure and expression may translate into phenotypic differences that can be acted upon by natural selection during the evolution of early generation allopolyploids.

Acknowledgments We thank James Weir, Eileen Iggo, Jacqueline McKenna, and the staff of the University of Stirling Research Glasshouses for support with plant growth, and Mariah Wuerges for help with data collection. We thank two anonymous reviewers for their constructive comments on a previous version of the manuscript. This work was funded by a Summer Studentship from the Department of Biological and Environmental Sciences, University of Stirling to SR, an Erasmus Traineeship to MQ, a Postdoctoral Fellowship from Plant Fellows to SM, and a Research Grant from the Botanical Society of Britain and Ireland (BSBI) to MVM.

Funding This work was funded by a Summer Studentship from the Department of Biological and Environmental Sciences, University of Stirling to SR, an Erasmus Traineeship to MQ, a Postdoctoral Fellowship from Plant Fellows to SM, and a Research Grant from the Botanical Society of Britain and Ireland (BSBI) to MVM.
Compliance with ethical standards

Conflict of interest The authors declare that they have no conflict of interest.

Open Access This article is distributed under the terms of the Creative Commons Attribution 4.0 International License (http://crea tivecommons.org/licenses/by/4.0/), which permits unrestricted use, distribution, and reproduction in any medium, provided you give appropriate credit to the original author(s) and the source, provide a link to the Creative Commons license, and indicate if changes were made.

\section{Information on Electronic Supplementary Material}

Online Resource 1. Floral and vegetative characteristics of F1 individuals produced through crosses within- (LED and STR), and between populations of Mimulus peregrinus $(\mathrm{STR} \times \mathrm{LED})$.

Online Resource 2. Floral and vegetative characteristics of F2 individuals produced through self-pollination of F1 individuals from crosses within- (LED and STR), and between populations $(\mathrm{STR} \times \mathrm{LED})$ of Mimulus peregrinus.

\section{References}

Ainouche ML, Baumel A, Salmon A, Yannic G (2004) Hybridization, polyploidy and speciation in Spartina (Poaceae). New Phytol 161:165-172. doi:10.1046/j.1469-8137.2003.00926.x

Arnold ML, Hodges SA (1995) Are natural hybrids fit or unfit relative to their parents. Trends Ecol Evol 10:67-71. doi:10.1016/S01695347(00)88979-X

Arnold ML, Martin NH (2010) Hybrid fitness across time and habitats. Trends Ecol Evol 25:530-536. doi:10.1016/j.tree.2010. 06.005

Arrigo N, Barker MS (2012) Rarely successful polyploids and their legacy in plant genomes. Curr Opin Pl Biol 15:140-146. doi:10. 1016/j.pbi.2012.03.010

Ashton PA, Abbott RJ (1992) Multiple origins and genetic diversity in the newly arisen allopolyploid species, Senecio cambrensis Rosser (Compositae). Heredity 68:25-32. doi:10.1038/hdy.1992. 3

Bates D, Maechler M, Bolker B, Walker S (2015) Fitting linear mixed-effects models using lme4. J Stat Softw 67:1-48. doi:10. 18637/jss.v067.i01

Beck JB, Allison JR, Pryer KM, Windham MD (2012) Identifying multiple origins of polyploid taxa: a multilocus study of the hybrid cloak fern (Astrolepis integerrima; Pteridaceae). Amer J Bot 99:1857-1865. doi:10.3732/ajb.1200199

Benedict BG, Modliszewski JL, Sweigart AL, Martin NH, Ganders FR, Willis JH (2012) Mimulus sookensis (Phrymaceae), a new allotetraploid species derived from Mimulus guttatus and Mimulus nasutus. Madroño 59:29-43. doi:10.3120/0024-963759.1.29

Buggs RJA (2013) The consequences of polyploidy and hybridisation for transcriptome dynamics unravelling gene expression of complex crop genomes. Heredity 110:97-98. doi:10.1038/hdy. 2012.61

Buggs RJA, Doust AN, Tate JA, Koh J, Soltis K, Feltus FA, Paterson AH, Soltis PS, Soltis DE (2009) Gene loss and silencing in Tragopogon miscellus (Asteraceae): comparison of natural and 
synthetic allotetraploids. Heredity 103:73-81. doi:10.1038/hdy. 2009.24

Buggs RJA, Zhang L, Miles N, Tate JA, Gao L, Wei W, Schnable PS, Barbazuk WB, Soltis PS, Soltis DE (2011) Transcriptomic shock generates evolutionary novelty in a newly formed, natural allopolyploid plant. Curr Biol 21:551-556. doi:10.1016/j.cub. 2011.02.016

Buggs RJA, Chamala S, Wu W, Tate JA, Schnable PS, Soltis DE, Soltis PS, Barbazuk WB (2012) Rapid, repeated, and clustered loss of duplicate genes in allopolyploid plant populations of independent origin. Curr Biol 22:248-252. doi:10.1016/j.cub. 2011.12.027

Burke JM, Arnold ML (2001) Genetics and the fitness of hybrids. Annual Rev Genet 35:31-52

Burke JM, Voss TJ, Arnold ML (1998) Genetic interactions and natural selection in Louisiana iris hybrids. Evolution 52:1304-1310. doi:10.2307/2411300

Burton RS, Pereira RJ, Barreto FS (2013) Cytonuclear genomic interactions and hybrid breakdown. Annual Rev Ecol Evol Syst 44:281-302. doi:10.1146/annurev-ecolsys-110512-135758

Chester M, Gallagher JP, Symonds VV, Cruz da Silva AV, Mavrodiev EV, Leitch AR, Soltis PS, Soltis DE (2012) Extensive chromosomal variation in a recently formed natural allopolyploid species, Tragopogon miscellus (Asteraceae). Proc Natl Acad Sci USA 109:1176-1181. doi:10.1073/pnas. 1112041109

Chester M, Lipman MJ, Gallagher JP, Soltis PS, Soltis DE (2013) An assessment of karyotype restructuring in the neoallotetraploid Tragopogon miscellus (Asteraceae). Chromosome Res 21:75-85. doi:10.1007/s10577-013-9339-y

Comai L (2005) The advantages and disadvantages of being polyploid. Nat Rev Genet 6:836-846. doi:10.1038/nrg1711

Comai L, Tyagi AP, Winter K, Holmes-Davis R, Reynolds SH, Stevens Y, Byers B (2000) Phenotypic instability and rapid gene silencing in newly formed Arabidopsis allotetraploids. Pl Cell 12:1551-1567. doi:10.1105/tpc.12.9.1551

Coyne JA, Orr HA (2004) Speciation. Sinauer Associates, Sunderland

Doyle JJ, Doyle JL, Brown AHD (1999) Origins, colonization, and lineage recombination in a widespread perennial soybean polyploid complex. Proc Natl Acad Sci USA 96:10741-10745. doi:10.1073/pnas.96.19.10741

Fetscher AE, Kohn JR (1999) Stigma behavior in Mimulus aurantiacus (Scrophulariaceae). Amer J Bot 86:1130-1135

Fishman L, Willis JH (2006) A cytonuclear incompatibility causes anther sterility in Mimulus hybrids. Evolution 60:1372-1381. doi:10.1554/05-708.1

Franzke A, Mummenhoff K (1999) Recent hybrid speciation in Cardamine (Brassicaceae): conversion of nuclear ribosomal ITS sequences in statu nascendi. Theor Appl Genet 98:831-834. doi:10.1007/s001220051140

Grant V (1966) Origin of a new species of Gilia in a hybridization experiment. Genetics 54:1189

Grant V (1971) Plant Speciation. Columbia University Press, New York

Hadfield JD (2010) MCMC methods for multi-response generalized linear mixed models: the MCMCglmm R Package. J Stat Softw 33:1-22

Hegarty MJ, Hiscock SJ (2008) Genomic clues to the evolutionary success of polyploid plants. Curr Biol 18:R435-R444. doi:10. 1016/j.cub.2008.03.043

Hegarty MJ, Barker GL, Wilson ID, Abbott RJ, Edwards KJ, Hiscock SJ (2006) Transcriptome shock after interspecific hybridization in Senecio is ameliorated by genome duplication. Curr Biol 16:1652-1659. doi:10.1016/j.cub.2006.06.071

Hegarty M, Coate J, Sherman-Broyles S, Abbott R, Hiscock S, Doyle J (2013) Lessons from natural and artificial polyploids in higher plants. Cytogenet Genome Res 140:204-225. doi:10.1159/ 000353361

Henry IM, Dilkes BP, Tyagi A, Gao J, Christensen B, Comai L (2014) The BOY NAMED SUE quantitative trait locus confers increased meiotic stability to an adapted natural allopolyploid of Arabidopsis. Pl Cell 26:181-194. doi:10.1105/tpc.113.120626

Hollister JD (2015) Polyploidy: adaptation to the genomic environment. New Phytol 205:1034-1039

Jiao Y, Wickett NJ, Ayyampalayam S, Chanderbali AS, Landherr L, Ralph PE, Tomsho LP, Hu Y, Liang H, Soltis PS et al. (2011) Ancestral polyploidy in seed plants and angiosperms. Nature 473:97-100. doi:10.1038/nature09916

Kearns CA, Inouye DW (1993) Techniques for Pollination Biologists. University Press of Colorado, Niwot

Koh J, Soltis PS, Soltis DE (2010) Homeolog loss and expression changes in natural populations of the recently and repeatedly formed allotetraploid Tragopogon mirus (Asteraceae). BMC Genom 11:97. doi:10.1186/1471-2164-11-97

Köhler C, Mittelsten Scheid O, Erilova A (2010) The impact of the triploid block on the origin and evolution of polyploid plants. Trends Genet 26:142-148. doi:10.1016/j.tig.2009.12.006

Kuznetsova A, Brockhoff PB, Christensen RHB (2016) lmerTest: tests in linear mixed effect models. $\mathrm{R}$ package version 2.0-30. Available at: http://www.R-project.org

Lafon-Placette C, Kohler C (2015) Epigenetic mechanisms of postzygotic reproductive isolation in plants. Curr Opin Pl Biol 23:39-44. doi:10.1016/j.pbi.2014.10.006

Levin DA (1975) Minority cytotype exclusion in local plant populations. Taxon 24:35-43

Levin DA (2002) The role of chromosomal change in plant evolution. Oxford University Press, Oxford

Levin DA (2003) The cytoplasmic factor in plant speciation. Syst Bot 28:5-11. doi:10.1043/0363-6445-28.15

Lim KY, Soltis DE, Soltis PS, Tate J, Matyasek R, Srubarova H, Kovarik A, Pires JC, Xiong ZY, Leitch AR (2008) Rapid chromosome evolution in recently formed polyploids in Tragopogon (Asteraceae). PLoS ONE. doi:10.1371/journal.pone. 0003353

Lindtke D, Buerkle CA (2015) The genetic architecture of hybrid incompatibilities and their effect on barriers to introgression in secondary contact. Evolution 69:1987-2004. doi:10.1111/evo. 12725

Liu B, Vega JM, Feldman M (1998) Rapid genomic changes in newly synthesized amphiploids of Triticum and Aegilops. II. Changes in low-copy coding DNA sequences. Genome 41:535-542. doi: $10.1139 / \mathrm{g} 98-052$

Madlung A (2013) Polyploidy and its effect on evolutionary success: old questions revisited with new tools. Heredity 110:99-104. doi:10.1038/hdy.2012.79

Madlung A, Tyagi AP, Watson B, Jiang HM, Kagochi T, Doerge RW, Martienssen R, Comai L (2005) Genomic changes in synthetic Arabidopsis polyploids. Pl J 41:221-230. doi:10.1111/j.1365313X.2004.02297.x

Mallet J (2007) Hybrid speciation. Nature 446:279-283. doi:10.1038/ nature 05706

Martin NH, Willis JH (2010) Geographical variation in postzygotic isolation and its genetic basis within and between two Mimulus species. Philos Trans Roy Soc B Biol Sci 365:2469-2478. doi:10.1098/rstb.2010.0030

Mavrodiev EV, Chester M, Suarez-Santiago VN, Visger CJ, Rodriguez R, Susanna A, Baldini RM, Soltis PS, Soltis DE (2015) Multiple origins and chromosomal novelty in the allotetraploid Tragopogon castellanus (Asteraceae). New Phytol 206:1172-1183. doi:10.1111/nph.13227

Mayrose I, Zhan SH, Rothfels CJ, Magnuson-Ford K, Barker MS, Rieseberg LH, Otto SP (2011) Recently formed polyploid plants 
diversify at lower rates. Science 333: 1257. doi:10.1126/science. 1207205

Modliszewski JL, Willis JH (2012) Allotetraploid Mimulus sookensis are highly interfertile despite independent origins. Molec Ecol 21:5280-5298. doi:10.1111/j.1365-294X.2012.05706.x

Modliszewski JL, Willis JH (2014) Near-absent levels of segregational variation suggest limited opportunities for the introduction of genetic variation via homeologous chromosome pairing in synthetic neoallotetraploid Mimulus. Genes Genomes Genet 4:509-522. doi:10.1534/g3.113.008441

Ozkan H, Levy AA, Feldman M (2001) Allopolyploidy-induced rapid genome evolution in the wheat (Aegilops-Triticum) group. Pl Cell 13:1735-1747. doi:10.2307/3871315

Pantoja PO, Simon-Porcar VI, Puzey JR, Vallejo-Marín M (2017) Genetic variation and clonal diversity in introduced populations of Mimulus guttatus assessed by genotyping at 62 single nucleotide polymorphism loci. Pl Ecol Div 10:5-15. doi:10. 1080/17550874.2017.1287785

Preston CD, Pearman DA, Dines TD (2002) New Atlas of the British and Irish Flora. Oxford University Press, Oxford

Puzey J, Vallejo-Marín M (2014) Genomics of invasion: diversity and selection in introduced populations of monkeyflowers (Mimulus guttatus). Molec Ecol 23:4472-4485. doi:10.1111/mec.12875

Ramsey J, Schemske DW (2002) Neopolyploidy in flowering plants. Annual Rev Ecol Syst 33:589-639. doi:10.1146/annurev.ecolsys. 33.010802.150437

Rieseberg LH (2001) Chromosomal rearrangements and speciation. Trends Ecol Evol 16:351-358. doi:10.1016/S01695347(01)02187-5

Rieseberg LH, Willis JH (2007) Plant speciation. Science 317:910-914. doi:10.1126/science.1137729

Rieseberg LH, Sinervo B, Linder CR, Ungerer MC, Arias DM (1996) Role of gene interactions in hybrid speciation: evidence from ancient and experimental hybrids. Science 272:741-745. doi:10. $1126 /$ science. 272.5262 .741

Sampson JF, Byrne M (2012) Genetic diversity and multiple origins of polyploid Atriplex nummularia Lindl. (Chenopodiaceae). Biol J Linn Soc 105:218-230. doi:10.1111/j.1095-8312.2011.01787.x

Segraves KA, Thompson JN, Soltis PS, Soltis DE (1999) Multiple origins of polyploidy and the geographic structure of Heuchera grossulariifolia. Molec Ecol 8:253-262. doi:10.1046/j.1365294X.1999.00562.x

Servick S, Visger CJ, Gitzendanner MA, Soltis PS, Soltis DE (2015) Population genetic variation, geographic structure, and multiple origins of autopolyploidy in Galax urceolata. Amer J Bot 102:973-982. doi:10.3732/ajb.1400554

Soltis PS, Soltis DE (1991) Multiple origins of the allotetraploid Tragopogon mirus (Compositae): rDNA Evidence. Syst Bot 16:407-413

Soltis DE, Soltis PS (1999) Polyploidy-recurrent formation and genome evolution. Trends Ecol Evol 14:348-352. doi:10.1016/ S0169-5347(99)01638-9

Soltis DE, Soltis PS, Pires JC, Kovarik A, Tate JA, Mavrodiev E (2004) Recent and recurrent polyploidy in Tragopogon (Asteraceae): cytogenetic, genomic and genetic comparisons. Biol J Linn Soc 82:485-501. doi:10.1111/j.1095-8312.2004.00335x

Soltis DE, Albert VA, Leebens-Mack J, Bell CD, Paterson AH, Zheng C, Sankoff D, dePamphilis CW, Wall PK, Soltis PS (2009) Polyploidy and angiosperm diversification. Amer $\mathrm{J}$ Bot 96:336-348. doi:10.3732/ajb.0800079

Soltis DE, Segovia-Salcedo MC, Jordon-Thaden I, Majure L, Miles NM, Mavrodiev EV, Mei WB, Cortez MB, Soltis PS, Gitzendanner MA (2014a) Are polyploids really evolutionary dead- ends (again)? A critical reappraisal of Mayrose et al. (2011). New Phytol 202:1105-1117. doi:10.1111/nph.12756

Soltis DE, Visger CJ, Soltis PS (2014b) The polyploidy revolution then... and now: Stebbins revisited. Amer J Bot 101:1057-1078

Soltis PS, Marchant DB, Van de Peer Y, Soltis DE (2015) Polyploidy and genome evolution in plants. Curr Opin Genet Developm 35:119-125. doi:10.1016/j.gde.2015.11.003

Song K, Lu P, Tang K, Osborn TC (1995) Rapid genome change in synthetic polyploids of Brassica and its implications for polyploid evolution. Proc Natl Acad Sci USA 92:7719-7723

Stace C (2010) New flora of the British Isles. Cambridge University Press, Cambridge

Stace CA, Preston CD, Pearman DA (2015) Hybrid flora of the British Isles. Botanical Society of Britain and Ireland, Bristol

Stebbins GL (1950) Variation and evolution in plants. Columbia University Press, New York

Sweigart AL, Mason AR, Willis JH (2007) Natural variation for a hybrid incompatibility between two species of Mimulus. Evolution 61:141-151. doi:10.1111/j.1558-5646.2007.00011.x

Tate JA, Ni ZF, Scheen AC, Koh J, Gilbert CA, Lefkowitz D, Chen ZJ, Soltis PS, Soltis DE (2006) Evolution and expression of homeologous loci in Tragopogon miscellus (Asteraceae), a recent and reciprocally formed allopolyploid. Genetics 173:1599-1611. doi:10.1534/10.1534/genetics.106.057646

Vallejo-Marín M (2012) Mimulus peregrinus (Phrymaceae)—a new British allopolyploid species. PhytoKeys 14:1-14. doi:10.3897/ phytokeys.14.3305

Vallejo-Marín M, Lye GC (2013) Hybridisation and genetic diversity in introduced Mimulus (Phrymaceae). Heredity 110:111-122. doi:10.1038/hdy.2012.91

Vallejo-Marín M, Hiscock SJ (2016) Hybridization and hybrid speciation under global change. New Phytol 211:1170-1187. doi:10.1111/nph.14004

Vallejo-Marín M, Buggs RJA, Cooley AM, Puzey JR (2015) Speciation by genome duplication: repeated origins and genomic composition of the recently formed allopolyploid species Mimulus peregrinus. Evolution 69:1487-1500. doi:10.1111/ evo. 12678

Vallejo-Marín M, Cooley AM, Lee MY, Folmer M, McKain MR, Puzey JR (2016) Strongly asymmetric hybridization barriers shape the origin of a new polyploid species and its hybrid ancestor. Amer J Bot 103:1272-1288. doi:10.3732/ajb.1500471

Vickery RK (1995) Speciation by aneuploidy and polyploidy in Mimulus (Scrophulariaceae). Great Basin Nat 55:174-176

Wendel JF (2000) Genome evolution in polyploids. Pl Molec Biol 42:225-249. doi:10.1023/A:1006392424384

Wright KM, Arnold B, Xue K, Surinova M, O'Connell J, Bomblies K (2015) Selection on meiosis genes in diploid and tetraploid Arabidopsis arenosa. Molec Biol Evol 32:944-955. doi:10.1093/ molbev/msu398

Wyatt R, Odrzykoski IJ, Stoneburner A, Bass HW, Galau GA (1988) Allopolyploidy in bryophytes: multiple origins of Plagiomnium medium. Proc Natl Acad Sci USA 85:5601-5604. doi:10.1073/ pnas.85.15.5601

Yant L, Bomblies K (2015) Genome management and mismanagement: cell-level opportunities and challenges of whole-genome duplication. Genes Developm 29:2405-2419. doi:10.1101/gad. 271072.115

Yant L, Hollister JD, Wright KM, Arnold BJ, Higgins JD, Franklin FCH, Bomblies K (2013) Meiotic adaptation to genome duplication in Arabidopsis arenosa. Curr Biol 23:2151-2156. doi:10.1016/j.cub.2013.08.059 